\title{
Comparison of efficacy of injection ferric carboxymaltose and iron sucrose in moderate anaemia in pregnancy
}

\author{
Kishna Ram, Kavita Arya, Nupur Hooja*, Neha Singh, Aditi Jaiswal
}

Department of Obstetrics and Gynecology, SMS Medical College, Jaipur, Rajasthan, India

Received: 04 May 2021

Revised: 30 May 2021

Accepted: 01 June 2021

\section{*Correspondence:}

Dr. Nupur Hooja,

E-mail: nupurhooja@gmail.com

Copyright: (C) the author(s), publisher and licensee Medip Academy. This is an open-access article distributed under the terms of the Creative Commons Attribution Non-Commercial License, which permits unrestricted non-commercial use, distribution, and reproduction in any medium, provided the original work is properly cited.

\begin{abstract}
Background: Prevalence of anaemia in pregnant women is $14 \%$ in developed and 58-89.6\% in pregnant Indian women. Parenteral iron is seems to be an option in the treatment of moderate iron deficiency anaemia which allow high doses of iron to be administered rapidly, in those who are intolerant to oral iron, have poor compliance to oral iron or gastrointestinal disorder. The objective was to compare the efficacy of newer drug, inravenous ferric carboxymaltose (FCM) with intravenous iron sucrose.

Methods: Group A were given injection FCM and group B were given injection iron sucrose. FCM was given in one or two sittings depending on iron requirement and iron sucrose was given in divided doses. Haemogram was done at baseline and on day 3 and 21 and at 12 weeks. All the observations were tabulated and analysed.

Results: The mean rise in haemoglobin values from baseline in the FCM group was $0.20 \pm 0.06$ at $3^{\text {rd }}$ day, $2.03 \pm 0.47$ at 3 weeks, $3.86 \pm 0.53$ at 12 weeks compared to iron sucrose group, which was $0.11 \pm 0.08$ at $3^{\text {rd }}$ day, $1.51 \pm 0.39$ at 3 weeks, and $3.22 \pm 0.54$ at 12 weeks, which was statistically significant and showed that the haemoglobin levels were increased more in FCM group. Target haemoglobin was achieved in $92 \%$ women in FCM group and $78 \%$ women in iron sucrose group.

Conclusions: Women in the FCM group achieved significantly higher haemoglobin level than in iron sucrose group. It was given in fewer sittings, hence was more convenient with better efficacy.
\end{abstract}

Keywords: Anaemia, Ferric carboxymaltose, Iron sucrose complex, Parenteral

\section{INTRODUCTION}

World Health Organization (WHO) has estimated that prevalence of anaemia in pregnant women is $14 \%$ in developed and $51 \%$ in developing countries. It is estimated that majority of women do not have adequate iron stores for pregnancy. ${ }^{1}$ Among pregnant Indian women, 58-89.6\% prevalence of anaemia has been documented. ${ }^{2}$

The first choice for prophylaxis and for treatment of mild iron deficiency anaemia in pregnancy is oral iron therapy. Effectiveness of oral iron is largely compromised by lack of absorption, poor compliance, increased adverse effects (up to 56\%) and discontinuation of treatment (up to $20 \%$ ). ${ }^{1}$
Blood transfusion has its own hazards including transfusion of wrong blood, deadly infections and anaphylaxis.

Women with moderate anaemia can be treated also with parenteral iron therapy depending upon individual basis (degree of anaemia, period of gestation and tolerance of therapy chosen etc.). Parenteral iron is seems to be an attractive option in the treatment of iron deficiency anaemia, likely to be more popular due to the introduction of new intravenous iron preparations, which allow high doses of iron to be administered rapidly. Indications of parenteral iron therapy are intolerance to oral iron, poor 
compliance to oral iron, gastrointestinal disorder, malabsorbtion syndrome. ${ }^{3}$

Various parenteral iron preparations are now available. Intravenous iron sucrose complex (IVIS) is given in multiple doses which requires women to come frequently. Newer drug, intravenous ferric carboxymaltose (FCM), can be infused in one or two doses, so they are more patient friendly. ${ }^{3}$ The objective was to compare the efficacy of intravenous ferric carboxymaltose and intravenous iron sucrose complex in pregnant women with moderate anaemia.

\section{METHODS}

This randomized comparative hospital-based longitudinal study was conducted in the Department of Obstetrics and Gynecology, SMS Medical College and Attached Group of Hospitals, Jaipur from July 2020 till December 2020.

Institutional review board and ethical committee approval was taken prior to the study.

\section{Inclusion criteria}

Women with singleton live pregnancy, 24-26 weeks period of gestation, $>18$ years of age with $\mathrm{Hb}$ level between 7-10 $\mathrm{gm} / \mathrm{dl}, \mathrm{MCV}<100 \mathrm{fl}$ and ferritin level <50 $\mu \mathrm{g}$ were selected for the study from the antenatal clinic.

\section{Exclusion criteria}

Women with medical disorders, suspected acute infection, prior parental iron treatment or blood transfusion, intolerance to iron derivatives, known haemoglobinopathies or women with transport difficulties were excluded.

Written informed consent was taken from all women who were participating in the study.

Sample size was calculated at $80 \%$ study power and $\alpha$ error of $0.05 \%$ assuming SD $0.51 \mathrm{gm} / \mathrm{dl}$ raise at four weeks in haemoglobin after Ferric carboxymaltose supplement as found in study of Mahajan et al. ${ }^{4}$ For a minimum detectable mean differences of $0.3 \mathrm{gm} / \mathrm{dl}$ in haemoglobin between two groups, 46 patients were required as sample size which were rounded off to 50 patients in each group as final sample at present study expecting $10 \%$ dropouts or attrition.

Group allocation was done by coin tossing method to allocate the first woman to group A. After that, they were allocated alternately in both groups. Group A were given injection FCM and group B were given injection iron sucrose. FCM was given in one or two sittings depending on iron requirement and iron sucrose was given in divided doses. The dose for IV iron in both groups was calculated from the following formula: Weight $\times$ (target haemoglobin - actual haemoglobin) $\times 0.24+1000 \mathrm{mg}$. The weight was the patient's weight before pregnancy (in kilograms). Target haemoglobin was set as $11 \mathrm{gm} / \mathrm{dl}$ and 0.24 is a correction factor that takes into account the patient's blood volume, estimated at $7 \%$ of body weight and haemoglobin iron content; $1000 \mathrm{mg}$ is the quantity of stored iron in adults. Haemogram was done at baseline and on day 3 and 21 and at 12 weeks. All the observations were recorded, statistical analysis done and conclusions drawn.

\section{Statistical analysis}

Continuous variables (quantitative data) were summarized as mean and standard deviation while nominal/categorical variables (qualitative data) were expressed as percentages and proportions. Unpaired t test and Pearson correlation coefficient was used for analysis of continuous variables while chi-square test and Fischer Exact test were used for nominal/categorical variables. Paired t test was used for analysis of paired data. $\mathrm{P}$ value $<0.05$ was taken as significant. Statistical analysis was done using computer software (Microsoft excel 2007). Statistics was calculated using NCSS 2020 software.

\section{RESULTS}

The mean age of the anaemic women was $24.74 \pm 4.176$ years with range of 19-34 years. Majority of the women in both the groups belonged to lower middle class (IV) and lower class (V) (62\%) and were educated upto high secondary, $54 \%$. Majority of women were second and third gravidae $(56 \%)$ and mean gestational age in the study was $24.99 \pm 0.943$ weeks with range of 24-26 weeks.

Mean basal $\mathrm{Hb}$ was $8.58 \pm 0.87 \mathrm{gm} / \mathrm{dl}, 8.53 \pm 0.75 \mathrm{gm} / \mathrm{dl}$ and mean values of serum ferritin, serum iron, transferrin saturation and TIBC were 7.17 $\pm 3.56 \mu \mathrm{g} / 1,12.49 \pm 4.87$ $\mu \mathrm{g} / \mathrm{dl}, \quad 3.55 \pm 2.10$ and $543.37 \pm 62.10 \mu \mathrm{g} / \mathrm{dl}$. All the parameters in the two groups were comparable with no significant difference before iron supplementation.

At $3^{\text {rd }}$ day post-treatment, mean rise in haemoglobin was more in FCM group than iron sucrose group $(0.1997 \mathrm{gm} / \mathrm{dl}$ versus $0.1141 \mathrm{gm} / \mathrm{dl}$ ), the rise being statistically significant $(\mathrm{p}<0.05)$.

At 21 days post-treatment, overall mean haemoglobin was higher (from $8.53 \pm 0.75$ to $10.53 \pm 0.69 \mathrm{gm} / \mathrm{dl}$ ) in FCM group as compared to that of iron sucrose group $(8.63 \pm 0.98$ to $10.15 \pm 0.95 \mathrm{gm} / \mathrm{dl}$ ), which was statistically significant $(\mathrm{p}=0.02)$. Mean rise in haemoglobin was also more in FCM group as compared to iron sucrose group $(2.03 \mathrm{gm} / \mathrm{dl}$ versus $1.51 \mathrm{gm} / \mathrm{dl}$ ) and this difference too was statistically significant $(\mathrm{p}=0.003)$ (Table 1$)$. 
Table 1: Haemoglobin level at different time in the study.

\begin{tabular}{|c|c|c|c|c|c|}
\hline Parameter & & & FCM group & Iron sucrose group & P value \\
\hline \multirow{7}{*}{$\mathbf{H b}$} & Baseline & Mean $\mathrm{Hb} \pm \mathrm{SD}$ & $8.53 \pm 0.75$ & $8.63 \pm 0.98$ & $\mathrm{P}=0.568, \mathrm{NS}$ \\
\hline & \multirow{2}{*}{$3^{\text {rd }}$ day } & Mean total $\mathrm{Hb} \pm \mathrm{SD}$ & $\begin{array}{l}8.73 \pm 0.75 \\
\text { pair } t=22.91 \\
p<0.05, \text { sig }\end{array}$ & $\begin{array}{l}8.75 \pm 0.97 \text { pair } \mathrm{t}=22.91 \\
\mathrm{p}<0.05, \text { sig }\end{array}$ & $\mathrm{P}=0.908, \mathrm{NS}$ \\
\hline & & Rise mean $\mathrm{Hb} \pm \mathrm{SD}$ & $0.20 \pm 0.06$ & $0.11 \pm 0.08$ & $\mathrm{P}<0.05$, sig \\
\hline & \multirow[t]{2}{*}{3 weeks } & Mean total $\mathrm{Hb} \pm \mathrm{SD}$ & $\begin{array}{l}10.53 \pm 0.69 \text { pair } \\
t=28.69 \\
p<0.001, \text { sig }\end{array}$ & $\begin{array}{l}10.15 \pm 0.95 \text { pair } \mathrm{t}=31.37 \\
\mathrm{p}<0.001, \text { sig }\end{array}$ & $\mathrm{P}=0.02$, sig \\
\hline & & Rise mean $\mathrm{Hb} \pm \mathrm{SD}$ & $2.03 \pm 0.47$ & $1.51 \pm 0.39$ & $\mathrm{P}=0.003, \mathrm{sig}$ \\
\hline & \multirow[t]{2}{*}{12 weeks } & Mean total $\mathrm{Hb} \pm \mathrm{SD}$ & $\begin{array}{l}12.38 \pm 0.90 \text { pair } \\
t=50.73 \\
p<0.001, \text { sig }\end{array}$ & $\begin{array}{l}11.86 \pm 0.91 \text { pair } \mathrm{t}=41.87 \\
\mathrm{p}<0.001, \text { sig }\end{array}$ & $\mathrm{P}<0.01$, sig \\
\hline & & Rise mean $\mathrm{Hb} \pm \mathrm{SD}$ & $3.86 \pm 0.53$ & $3.22 \pm 0.54$ & $\mathrm{P}<0.001$, sig \\
\hline
\end{tabular}

Table 2: Rise in haemoglobin at 12 weeks post treatment.

\begin{tabular}{|c|c|c|c|c|c|c|c|c|}
\hline \multirow{3}{*}{$\begin{array}{l}\text { Pre-treatment } \\
\mathrm{Hb}(\mathrm{gm} / \mathrm{dl})\end{array}$} & \multicolumn{4}{|c|}{ FCM group $(n=50)$} & \multicolumn{4}{|c|}{ Iron sucrose group $(n=50)$} \\
\hline & \multirow{2}{*}{ No } & \multicolumn{3}{|c|}{ Rise in haemoglobin } & \multirow{2}{*}{ No } & \multicolumn{3}{|c|}{ Rise in haemoglobin } \\
\hline & & 2.0-3.0 & $3.1-4.0$ & 4.1-5.0 & & $2.0-3.0$ & $3.1-4.0$ & $4.1-5.0$ \\
\hline 7-7.9 & 15 & 1 & 10 & 4 & 14 & 3 & 9 & 2 \\
\hline 8-8.9 & 18 & 3 & 9 & 6 & 17 & 6 & 10 & 1 \\
\hline $9-10$ & 17 & 1 & 11 & 5 & 19 & 10 & 9 & 0 \\
\hline Total & 50 & 5 & 30 & 15 & 50 & 19 & 28 & 3 \\
\hline
\end{tabular}

At 12 weeks post-treatment also, overall mean haemoglobin was higher (from $8.53 \pm 0.75$ to $12.38 \pm 0.90$ $\mathrm{gm} / \mathrm{dl}$ ) in FCM group as compared to that in iron sucrose group $(8.63 \pm 0.98$ to $11.86 \pm 0.91 \mathrm{gm} / \mathrm{dl})$, which was statistically significant $(\mathrm{p}<0.01)$. Mean rise in haemoglobin was more in FCM group as compare to iron sucrose group (3.86 gm/dl versu $3.22 \mathrm{gm} / \mathrm{dl})$. This difference was statistically highly significant $(\mathrm{p}<0.001)$ (Table 1).

12 weeks after treatment, all women had rise in haemoglobin in both group, A rise in haemoglobin of 4.1 to $5.0 \mathrm{gm} / \mathrm{dl}$ in FCM group was seen in $30 \%$ women but in iron sucrose group in only $6 \%$ women. The rise was more in 7.0-7.9 $\mathrm{gm} / \mathrm{dl}$ as compared to higher haemoglobin levels in both the groups (Table 2).

It was observed that in the both groups all the other hematological parameters also changed significantly after 12 weeks treatment in both the groups from the baseline. Mean changes in mean corpuscular volume (MCV), mean corpuscular haemoglobin $(\mathrm{MCH})$, mean corpuscular haemoglobin concentration (MCHC) and red cell distribution width (RDW) were slightly higher in FCM group than in iron sucrose group but the difference was not statistically significant (Table 3 ).
Table 3: Mean rise in various haematological parameters in both the groups after 12 weeks.

\begin{tabular}{|c|c|c|c|}
\hline \multirow[t]{2}{*}{ Parameters } & $\begin{array}{l}\text { FCM } \\
\text { group } \\
(\mathrm{N}=50)\end{array}$ & $\begin{array}{l}\text { Iron } \\
\text { sucrose } \\
\text { group } \\
(\mathbf{N}=\mathbf{5 0})\end{array}$ & \multirow[t]{2}{*}{ P value } \\
\hline & $\begin{array}{l}\text { Mean } \\
\text { rise } \pm \text { SD }\end{array}$ & $\begin{array}{l}\text { Mean } \\
\text { rise } \pm \text { SD }\end{array}$ & \\
\hline MCV & $14.87 \pm 8.11$ & $14.80 \pm 6.05$ & $\begin{array}{l}t=0.048 \\
p=0.961, \\
N S\end{array}$ \\
\hline МСH & $7.87 \pm 2.43$ & $7.69 \pm 2.83$ & $\begin{array}{l}\mathrm{t}=0.341 \\
\mathrm{p}=0.733 \\
\mathrm{NS}\end{array}$ \\
\hline МСНС & $2.53 \pm 1.54$ & $2.30 \pm 1.89$ & $\begin{array}{l}\mathrm{t}=0.667 \\
\mathrm{p}=0.506 \\
\mathrm{NS}\end{array}$ \\
\hline RDW & $-4.37 \pm 2.46$ & $-4.32 \pm 2.21$ & $\begin{array}{l}t=-0.106 \\
p=0.915, \\
N S\end{array}$ \\
\hline
\end{tabular}

In the present study, target haemoglobin was achieved in $92 \%$ women in FCM group and $78 \%$ women in iron sucrose group. This difference was significant $(\mathrm{p}=0.04)$ (Table 4). 
Table 4: Correction of anaemia in the two groups.

\begin{tabular}{|c|c|c|c|c|c|c|}
\hline \multirow{2}{*}{$\begin{array}{l}\text { Hb } \\
\text { level }\end{array}$} & \multicolumn{2}{|c|}{$\begin{array}{l}\text { FCM group } \\
(\mathbf{N}=\mathbf{5 0})\end{array}$} & \multicolumn{2}{|c|}{$\begin{array}{l}\text { Iron sucrose } \\
\text { group }(\mathbf{N}=\mathbf{5 0})\end{array}$} & \multicolumn{2}{|c|}{ Total } \\
\hline & No. & $\%$ & No. & $\%$ & No. & $\%$ \\
\hline $\begin{array}{l}<11 \\
\mathrm{gm} / \mathrm{dl}\end{array}$ & 4 & 8 & 11 & 22 & 15 & 15 \\
\hline $\begin{array}{l}\geq 11 \\
\mathrm{gm} / \mathrm{dl} *\end{array}$ & 46 & 92 & 39 & 78 & 85 & 85 \\
\hline Total & 50 & 100 & 50 & 100 & 100 & 100 \\
\hline
\end{tabular}

$\chi^{2}=3.84, \mathrm{df}=1, \mathrm{p}=0.04 \mathrm{sig}$

\section{DISCUSSION}

Ferric carboxymaltose consists of a ferric hydroxide core stabilized by a carbohydrate shell and has very high stability and half-life (16 hours). On administering, it allows for controlled delivery of iron within the cells of the reticuloendothelial system and subsequent delivery to the iron-binding proteins ferritin and transferrin, with minimal risk of release of large amounts of ionic iron in the serum thus allows rapid administration of high doses of iron in a single sitting. ${ }^{5}$

We observed higher increase in haemoglobin in FCM group than iron sucrose group at each point of measurement. The mean rise in haemoglobin values from baseline in the FCM group was $0.20 \pm 0.06$ at $3^{\text {rd }}$ day, $2.03 \pm 0.47$ at 3 weeks, $3.86 \pm 0.53$ at 12 weeks compared to iron sucrose group, which was $0.11 \pm 0.08$ at $3^{\text {rd }}$ day, $1.51 \pm 0.39$ at 3 weeks, and $3.22 \pm 0.54$ at 12 weeks, which was statistically significant and showed that the haemoglobin levels were increased more in FCM group.

Similar to the present study, Jose et al also observed that the FCM group achieved significantly higher haemoglobin level than iron sucrose group $(10.6 \pm 1.21$ versus $10.01 \pm 0.71 \mathrm{p}$ value $\leq 0.003)$ in three weeks and $(11.53 \pm 0.46$ versus $10.8 \pm 0.44 \mathrm{gm} / \mathrm{dl})$ at 12 weeks. Total rise in mean haemoglobin level was also more in FCM group as compared to iron sucrose group (2.96 versus 2.21 $\mathrm{gm} / \mathrm{dl}$ ), the rise being highly significant statistically $(\mathrm{p}<0.001) .^{3}$

In a comparative study, Mahajan et al also found that in both the groups there was a significant increase in haemoglobin level. At four weeks post-treatment, mean total $\mathrm{Hb}$ level was significantly higher in FCM group as compared to that of iron sucrose group (10.29 versus 9.57 $\mathrm{gm} / \mathrm{dl} ; \mathrm{p}<0.0001)$. At 4 weeks post treatment, rise in mean haemoglobin level was more in FCM group as compared to iron sucrose group (1.80 versus $1.09 \mathrm{gm} / \mathrm{dl})$, the rise being highly significant statistically $(\mathrm{p}<0.001) .{ }^{4}$

Other authors, Swetha et al, Khan et al also found increase in haemoglobin from baseline to 4 weeks in each group, but the increase in haemoglobin in FCM group was more than iron sucrose group at each point of measurement. ${ }^{6,7}$
Comparison with other studies is difficult because of different criteria of inclusion, different method and different cut-offs used for lab parameters.

Jose et al observed mean change in MCV, MCH, MCHC and RDW was slightly higher in FCM group than iron sucrose at 12 weeks post treatment. ${ }^{3}$ Mahajan et al also found significant improvement of all parameters in both the groups but the difference between the groups was insignificant with other parameters. ${ }^{4}$ This study was similar to the present study. Swetha et al also found mean rise in $\mathrm{MCV}, \mathrm{MCH}$ and $\mathrm{MCHC}$ to be higher in FCM group than iron sucrose at 2 weeks post treatment. There was no significant different in all rise in both the groups. ${ }^{6}$

Jose et al also observed that, $82 \%$ of women in FCM and only $70 \%$ in Iron sucrose group had $\mathrm{Hb}>11 \mathrm{gm} \%$ respectively after 12 weeks. In attaining the target haemoglobin levels, the difference between the two groups was statistically significant. ${ }^{3}$ Lunagariya et al reported that target haemoglobin of $11 \mathrm{gm} / \mathrm{dl}$ was attained by $14 \%$ of the patients in the FCM group after 2 week of treatment as compared with $6 \%$ of patients in the iron sucrose group, which was statistically significant. This study compared levels after 2 weeks only. ${ }^{8}$

Verma et al, reported that $100 \%$ cases achieved target haemoglobin at 12 weeks after FCM therapy while in $98 \%$ cases achieved target haemoglobin at 12 weeks after iron sucrose therapy. ${ }^{9}$ This study was similar but achieved better correction than the present study.

There are some limitations of the study. Although FCM and iron sucrose replenishes stores, women were not followed upto term to determine whether $\mathrm{Hb}$ and serum ferritin level were maintained till delivery and lactation. Only i.v. routes were compared. The oral and i.m. route was not compared in the study.

\section{CONCLUSION}

Women in the FCM group achieved significantly higher haemoglobin level than in iron sucrose group. It was given in fewer sittings, hence was more convenient with better efficacy. Hence, it may be recommended as a treatment option in women with iron deficiency anaemia, nonresponding to oral therapy even at peripheral health centre.

\section{Funding: No funding sources}

Conflict of interest: None declared

Ethical approval: The study was approved by the Institutional Ethics Committee

\section{REFERENCES}

1. World Health Organisation. The Prevalence of anemia in women. WHO: Geneva, Switzerland; 2017.

2. National Health Policy 2017. New Delhi: Ministry of Health and Family Welfare, Government of India; 2017. Available from: 
https://www.nhp.gov.in/nhpfiles/national_health_pol icy_2017.pdf. Accessed on 15 January 2018.

3. Jose A, Mahey R, Sharma JB, Bhatla N, Saxena R, Kalaivani M, et al. Comparison of ferric Carboxymaltose and iron sucrose complex for treatment of iron deficiency anemia in pregnancyrandomised controlled trial. BMC Pregnancy Childbirth. 2019;19(1):1-8.

4. Geisser P. The pharmacology and safety profile of ferric carboxymaltose (Ferinject): structure/reactivity relationships of iron preparations. Portuguese $\mathbf{J}$ Nephrol Hypertens. 2009;23(1):11-6.

5. Mahajan A, Bhagat BR, Gupta S, Mahajan B, Verma M. A comparative study of efficacy and safety of intravenous ferric carboxymaltose versus iron sucrose in the treatment of iron deficiency anaemia of pregnancy in a tertiary care hospital. Int $\mathbf{J}$ Reprod Contracept Obstet Gynecol. 2018;7:1938-42.

6. Swetha T, Yasodha S, Prabhu R. Comparative study of efficacy and safety of anaemia correction between iron sucrose versus ferric carboxymaltose in pregnancy. IOSR J Dent Med Sci. 2019;18(6):45-8.
7. Khan S, Gupta S. A comparative study of injection ferric carboxymaltose and iron sucrose in anaemia complicating pregnancy. Int J Contemp Med Res. 2019;6(8):H6-9.

8. Lunagariya M, Nakum KD, Vithal A, Patel J, Patel M. Iron sucrose versus ferric carboxymaltose: in search of better treatment option in cases of post partum iron deficiency anemia. Int $\mathbf{J}$ Contemp Med Res. 2018;5(1):12-6.

9. Verma U, Singh S, Chandra M, Chandra M, Garg R, Singh $\mathrm{S}$, et al. To evaluate the efficacy and safety of single dose intravenous iron carboxymaltose verses multidose iron sucrose in postpartum cases of severe iron deficiency anemia. Int J Reprod Contracept Obstet Gynecol. 2015;4:442-6.

Cite this article as: Ram K, Arya K, Hooja N, Singh $\mathrm{N}$, Jaiswal A. Comparison of efficacy of injection ferric carboxymaltose and iron sucrose in moderate anaemia in pregnancy. Int $\mathrm{J}$ Reprod Contracept Obstet Gynecol 2021;10:2794-8. 